\title{
Contrast-enhanced voiding urosonography with intravesical administration of ultrasound contrast agent for the diagnosis of pediatric vesicoureteral reflux
}

\author{
WEI ZHANG ${ }^{1}$, BAOHUAN CAI ${ }^{2}$, XIAOLE ZHANG $^{2}$, \\ JIANHUA ZHOU ${ }^{2}$, LIRU QIU ${ }^{2}$ and HUIMING YI ${ }^{1}$ \\ Departments of ${ }^{1}$ Ultrasound and ${ }^{2}$ Pediatrics, Tongji Hospital, Tongji Medical College, \\ Huazhong University of Science and Technology, Wuhan, Hubei 430030, P.R. China
}

Received November 16, 2017; Accepted May 11, 2018

DOI: $10.3892 /$ etm.2018.6793

\begin{abstract}
Vesicoureteral reflux (VUR) is one of the most common urinary tract anomalies in children. It has been reported that VUR may be associated with reflux nephropathy. Ultrasound contrast-enhanced voiding urosonography (CeVUS) has become a routine diagnostic method for VUR in a number of European countries; however, it is not widely used in China. The aim of the present study was to analyze the clinical application and evaluate the safety of CeVUS as a diagnostic tool for VUR in children in order to establish a standardized operating procedure for CeVUS in pediatric VUR in China. Between August 2016 and October 2017, 90 children who were susceptible to VUR were admitted into the Pediatric Nephrology Department of Tongji Hospital and underwent CeVUS. The SonoVue second-generation USA contrast agent was administered intravesically via a transurethral bladder catheter at a dose of $1 \mathrm{ml}$. The occurrence of adverse events was monitored. Urine analysis and culture were performed. A total of 90 children (47 female, 43 male; mean age, 36.6 months) with 178 Pelvi-Ureteral Units (PUUs) underwent CeVUS to screen for VUR. VUR was detected in 44/90 pediatric patients $(48.89 \%)$ and 65/178 PUUs $(36.52 \%)$ by CeVUS. The grade distribution of the 65 PUUs with VUS was as follows: Grade I, 3; Grade II, 9; Grade III, 14; Grade IV, 22; and Grade V, 17. The accuracy of CeVUS in the present study were consistent with previous reports. No urethral anomalies were detected and there were no adverse events. CeVUS was demonstrated to be a safe, accurate and reliable imaging technique for detecting VUR in high-risk
\end{abstract}

Correspondence to: Dr Huiming Yi, Department of Ultrasound, Tongji Hospital, Tongji Medical College, Huazhong University of Science and Technology, 1095 Jiefang Avenue, Wuhan, Hubei 430030, P.R. China

E-mail: yihuimingtj@sina.com

Key words: contrast-enhanced voiding urosonography, vesicoureteric reflux, children, urinary tract infection children, including neonates. Results of the present study indicated that CeVUS can be adopted as the primary screening and follow-up method for pediatric VUR diagnoses in China.

\section{Introduction}

Vesicoureteral reflux (VUR) is one of the most common anomalies of the urinary tract in children and is associated with reflux nephropathy (1). It is particularly important to perform screening for VUR in children with hydronephrosis at the fetal stage or repetitive febrile infection of the urinary tract to avoid the development of reflex nephropathy (2). However, the correlation between VUR and chronic nephropathy remains controversial (3). It is often recommended that high-risk children should be excluded from VUR, particular for those with hydronephrosis, scarred kidney and complicated infection of the urinary tract (4). At present, three methods are typically used to diagnose VUR: Retrograde voiding cystourethrogram with X-ray (VCUG), radionuclide cystography (RNC) and contrast-enhanced voiding urosonography (CeVUS) (5). The first two methods involve irradiation and intermittent imaging, and thus have limited sensitivity (6). Following the development of second-generation contrast agents and high definition ultrasound equipment, CeVUS has become the primary screening method for children with suspected VUR in Europe, with a diagnostic accuracy of $78-96 \%(7,8)$. CeVUS has $80-100 \%$ sensitivity, 77-97\% specificity and an increased positive diagnosis rate compared with VCUG and RNC (9-11). In addition, ultrasound has the advantage of being radiation-free, which allows for longer scanning times, making VUR screening in children more practical and allowing for repeated follow up scans. However, CeVUS is not popular in China and there is no standard operating practice for the procedure (7). The aim of the present study was to analyze the sensitivity and safety of CeVUS as a diagnostic tool for VUR in children and to develop a standard procedure for its clinical application in China.

\section{Materials and methods}

General information. A total of 90 Chinese children with repetitive urinary tract infection, complicated urinary tract 
infection, hydrophrosis at the fetal stage or abnormal urine at birth were enrolled in the present study. All participants were considered to be at a high risk for developing VUR. Patients were admitted to the Pediatric Nephrology Department of Tongji Hospital (Wuhan, China) between August 2016 and October 2017. Of these patients, 47 were female and 43 were male. A total of 2 newborn cases were included and the mean age was 36.6 months (range, 0.5-155 months). Study protocols were approved by the Institutional Review Board of Tongji Hospital (Huazhong University of Science and Technology, Wuhan, China; study ID, TJ-C 20160311) and informed consent was signed by the guardians of all participants.

CeVUS examination. All children were subjected to middle-segment urine culture, and the bacterial number was calculated. The bladder volume of the children was calculated using the following equation: Volume $(\mathrm{ml})=(\mathrm{age}$ in years + 2) x30 (7). Prior to examination, a urinary catheter was placed in the bladder and connected to a stopcock. After the bladder was emptied of urine, the catheter was clipped and the stopcock was closed. Patients were placed in the spine position without a sedative. The bilateral kidneys were recorded using a color LOGIQ E9 Ultrasound Doppler equipped with built-in harmonic imaging software and a $4 \mathrm{MHz}$ convex array harmonic imaging probe (GE Healthcare, Chicago, IL, USA) to assess the morphology, renal parenchyma echo, the collecting system and the bilateral ureters. The images were captured with a mechanical index of 0.08 . The SonoVue ${ }^{\circledR}$ contrast agent (Bracco, Milan, Italy), the major component of which is sulphur hexafluoride powder-coated with liposomes. Prior to examination, the contrast agent $(59 \mathrm{mg})$ was mixed with $5 \mathrm{ml}$ aseptic saline and agitated evenly to form a solution of microbubbles (diameter, $<10 \mu \mathrm{m})$. Warm saline at 1/3 of the bladder volume and $1 \mathrm{ml}$ microbubble solution were perfused into the bladder via the catheter. Warm saline (2/3 of the bladder volume) was continuously dripped into the bladder using infusion apparatus at a height of $1 \mathrm{~m}$. The catheter was opened and children were asked to urinate, with pressure as required on the bladder to push the urine out. After the contrast agent was injected, contrast ultrasound images were captured to continuously scan the unilateral renal pelvis, ureter and bladder. The steps of contrast ultrasound imaging were repeated for the contralateral renal pelvis and the ureter. The perineum was also scanned to examine the urethra. Preventive antibiotics (cefaclor $20 \mathrm{mg} / \mathrm{kg}$ ) were used prior to, during and after the examination.

VCUG examination. Cyclic VCUG was conducted using a digital fluoroscopic system (Siemens AG, Munich, Germany) according to a previous study (12). Briefly, intermittent pulsed fluoroscopy was performed in all the patients. The bladder was filled with radiographic contrast agent at body temperature using a trough urinary catheter by drip infusion. Two films were captured during the filling phase, one or two films were captured during voiding and one film was captured post voiding. VUR was diagnosed when radiographic contrast medium was observed in the ureter or pelvicalyceal system and was graded according to the International Reflux System of grading (7).
VUR grading standard. VUR was graded according to the following criteria: Grade I, contrast agent present only in the ureter; Grade II, contrast agent present in the ureter and renal pelvis without dilation of the renal pelvis; Grade III, contrast agent present in the ureter and renal pelvis with mild dilation of the renal pelvis; Grade IV, contrast agent present in the ureter and renal pelvis with dilations of the pelvis and calices, and clear carcunculae paillaris; Grade V, contrast agent present in the ureter and pelvis, with clear dilation of the pelvis and calices, disappearance of carcunculae paillaris and tortuous expansion of the ureter.

Statistical analysis. Statistical analysis was performed using SPSS 11.0 (SPSS, Inc., Chicago, IL, USA) software. Data were presented as mean $\pm \mathrm{SD}$. The Chi-square test was used to determine statistical differences between the groups. $\mathrm{P}<0.05$ was considered to indicate a statistically significant difference.

\section{Results}

Clinical data. A total of 90 children were enrolled in the present study, including 1 with left repetitive kidney and 3 with unilateral kidney (Table I; Figs. 1 and 2), resulting in a total of 178 Pyelo-Ureteral Units (PUUs). The colonies of bacterial over a specific area reached $>10^{5} / \mathrm{ml}$ in 25 cases. Kidney function was normal in all children (estimated glomerular filtration rate, $>110 \mathrm{ml} / 1.73 \mathrm{~m}^{2} / \mathrm{min}$ ). Urine examination revealed that 88 children were considered to have a urinary tract infection, which presented $\geq 2$ times. The remaining 2 newborns exhibited white blood cells in their urine. Detailed patient information is presented in Table I.

VUR detection with CeVUS. The CeVUS examination revealed that $44 / 90$ children $(48.89 \%)$ had VUR, including 23 cases of unilateral VUR and 21 cases of bilateral VUR (Table II). A total of 27 females and 17 males $(39.53 \%)$ were diagnosed with VUR (57.45\%) 1. Of the 178 PUUs, 65 were diagnosed with VUR (36.52\%), including 32/88 left PUUs (36.36\%) and $33 / 90$ right PUUs $(36.67 \%)$. The grades of diagnosed VURs are listed in Table III and representative images of patients with CeVUS are presented in Figs. 3-7.

Urine culture and VUR diagnosis using CeVUS. In the 25 children with a positive urine culture prior to CeVUS examination, $20(80 \%)$ were diagnosed with VUR, including 19 at Grade III or higher $(95 \%)$ and 11 at Grade V or higher $(55 \%)$. There were 14 cases of VUR at Grade V, 11 (78.57\%) of which were positive for urine culture. In the 5 cases with positive urine culture but negative VUR as assessed by CeVUS examination, 2 (49 and 56) were neurogenic bladder, 1 (35) had a larger bladder volume and 2 (22 and 34) were negative, as confirmed by repeated VCUG.

A total of 2 patients (number 4 and 23) were diagnosed with Grade III VUR by CeVUS, although the VCUG examination was negative. Patient 15 was diagnosed with Grade II/III VUR by VCUG, but CeVUS gave a diagnosis of Grade III/IV.

SonoVue concentration for VUR screening using CeVUS. The mean bladder volume was $151.5 \mathrm{ml}$ and the mean SonoVue concentration was $0.88 \%(0.22-1.63 \%$; Table I). 
Table I. Clinical data of the children enrolled in the study.

\begin{tabular}{|c|c|c|c|c|c|c|c|}
\hline \multirow[b]{2}{*}{ No. } & \multirow[b]{2}{*}{ Sex } & \multirow[b]{2}{*}{ Age (months) } & \multirow{2}{*}{$\begin{array}{c}\text { Bladder } \\
\text { volume }(\mathrm{ml})\end{array}$} & \multirow{2}{*}{$\begin{array}{c}\text { SonoVue } \\
\text { concentration }(\%)\end{array}$} & \multicolumn{2}{|c|}{ VUR degrade } & \multirow[b]{2}{*}{ Urine culture } \\
\hline & & & & & $\mathrm{L}$ & $\mathrm{R}$ & \\
\hline 1 & $\mathrm{~F}$ & 8 & 80.0 & 1.25 & $\mathrm{~N}$ & III & К.рпеи \\
\hline 2 & $\mathrm{~F}$ & 7 & 77.5 & 1.29 & II & $\mathrm{N}$ & $\mathrm{N}$ \\
\hline 3 & $\mathrm{~F}$ & 114 & 345.0 & 0.29 & I & II & E. coli \\
\hline 4 & $\mathrm{~F}$ & 41 & 162.5 & 0.62 & III & $\mathrm{N}$ & $\mathrm{N}$ \\
\hline 5 & $\mathrm{~F}$ & 49 & 182.5 & 0.55 & $\mathrm{~N}$ & $\mathrm{~N}$ & $\mathrm{~N}$ \\
\hline $6^{\mathrm{a}}$ & $\mathrm{F}$ & 0.5 & 61.25 & 1.63 & $\mathrm{~V} / \mathrm{N}^{*}$ & $\mathrm{~V}$ & E.faeci \\
\hline 7 & $\mathrm{~F}$ & 134 & 395.0 & 0.25 & IV & I & E. coli \\
\hline 8 & $\mathrm{~F}$ & 4 & 70.0 & 1.43 & $\mathrm{~N}$ & V & E. faeci \\
\hline 9 & $\mathrm{~F}$ & 94 & 295.0 & 0.34 & $\mathrm{~N}$ & $\mathrm{~N}$ & $\mathrm{~N}$ \\
\hline 10 & $\mathrm{~F}$ & 1 & 62.5 & 1.60 & $\mathrm{~N}$ & $\mathrm{~N}$ & $\mathrm{~N}$ \\
\hline 11 & $\mathrm{~F}$ & 40 & 160.0 & 0.63 & II & IV & K. рпеи \\
\hline 12 & $\mathrm{~F}$ & 10 & 85.0 & 1.18 & $\mathrm{~N}$ & $\mathrm{~N}$ & $\mathrm{~N}$ \\
\hline 13 & $\mathrm{~F}$ & 76 & 250.0 & 0.40 & $\mathrm{~N}$ & I & $\mathrm{N}$ \\
\hline 14 & $\mathrm{~F}$ & 3 & 67.5 & 1.48 & IV & III & $\mathrm{N}$ \\
\hline 15 & $\mathrm{~F}$ & 27 & 127.5 & 0.78 & III & IV & $\mathrm{N}$ \\
\hline 16 & $\mathrm{~F}$ & 7 & 77.5 & 1.29 & $\mathrm{~N}$ & $\mathrm{~N}$ & $\mathrm{~N}$ \\
\hline 17 & $\mathrm{~F}$ & 90 & 285.0 & 0.35 & $\mathrm{~N}$ & $\mathrm{~N}$ & $\mathrm{~N}$ \\
\hline 18 & $\mathrm{~F}$ & 7 & 77.5 & 1.29 & IV & IV & E. coli \\
\hline 19 & $\mathrm{~F}$ & 32 & 140.0 & 0.71 & III & $\mathrm{N}$ & $\mathrm{N}$ \\
\hline 20 & $\mathrm{~F}$ & 93 & 292.5 & 0.34 & $\mathrm{~N}$ & $\mathrm{~N}$ & $\mathrm{~N}$ \\
\hline 21 & $\mathrm{~F}$ & 45 & 172.5 & 0.58 & $\mathrm{~N}$ & $\mathrm{~N}$ & $\mathrm{~N}$ \\
\hline 22 & $\mathrm{~F}$ & 15 & 97.5 & 1.03 & $\mathrm{~N}$ & $\mathrm{~N}$ & E. coli \\
\hline 23 & $\mathrm{~F}$ & 29 & 132.5 & 0.75 & $\mathrm{~N}$ & III & $\mathrm{N}$ \\
\hline 24 & $\mathrm{~F}$ & 104 & 320.0 & 0.31 & $\mathrm{~N}$ & $\mathrm{~N}$ & $\mathrm{~N}$ \\
\hline 25 & $\mathrm{~F}$ & 9 & 82.5 & 1.21 & $\mathrm{~N}$ & $\mathrm{~N}$ & $\mathrm{~N}$ \\
\hline 26 & $\mathrm{~F}$ & 6 & 75.0 & 1.33 & $\mathrm{~N}$ & III & $\mathrm{N}$ \\
\hline 27 & $\mathrm{~F}$ & 54 & 195.0 & 0.51 & II & III & E. coli \\
\hline 28 & $\mathrm{~F}$ & 36 & 150.0 & 0.67 & IV & $\mathrm{N}$ & $\mathrm{N}$ \\
\hline 29 & $\mathrm{~F}$ & 3 & 67.5 & 1.48 & IV & $\mathrm{V}$ & P. aeru \\
\hline 30 & $\mathrm{~F}$ & 44 & 170.0 & 0.59 & Abs & $\mathrm{N}$ & $\mathrm{N}$ \\
\hline 31 & $\mathrm{~F}$ & 17 & 102.5 & 0.98 & Abs & III & $\mathrm{N}$ \\
\hline 32 & $\mathrm{~F}$ & 72 & 240.0 & 0.42 & $\mathrm{~N}$ & $\mathrm{~N}$ & $\mathrm{~N}$ \\
\hline 33 & $\mathrm{~F}$ & 3 & 67.5 & 1.48 & IV & IV & E. coli \\
\hline 34 & $\mathrm{~F}$ & 96 & 300.0 & 0.33 & $\mathrm{~N}$ & $\mathrm{~N}$ & E. coli \\
\hline 35 & $\mathrm{~F}$ & 93 & 292.5 & 0.34 & $\mathrm{~N}$ & $\mathrm{~N}$ & E. coli \\
\hline 36 & $\mathrm{~F}$ & 113 & 342.5 & 0.29 & $\mathrm{~N}$ & $\mathrm{~N}$ & $\mathrm{~N}$ \\
\hline 37 & $\mathrm{~F}$ & 40 & 160.0 & 0.63 & $\mathrm{~N}$ & IV & $\mathrm{N}$ \\
\hline 38 & $\mathrm{~F}$ & 3 & 67.5 & 1.48 & $\mathrm{~N}$ & $\mathrm{~N}$ & $\mathrm{~N}$ \\
\hline 39 & $\mathrm{~F}$ & 4 & 70.0 & 1.43 & IV & $\mathrm{V}$ & E. coli \\
\hline 40 & $\mathrm{~F}$ & 60 & 210.0 & 0.48 & II & II & $\mathrm{N}$ \\
\hline 41 & $\mathrm{~F}$ & 57 & 202.5 & 0.49 & II & $\mathrm{N}$ & $\mathrm{N}$ \\
\hline 42 & $\mathrm{~F}$ & 37 & 152.5 & 0.66 & IV & $\mathrm{N}$ & $\mathrm{N}$ \\
\hline 43 & $\mathrm{~F}$ & 9 & 82.5 & 1.21 & III & $\mathrm{N}$ & $\mathrm{N}$ \\
\hline 44 & $\mathrm{~F}$ & 11 & 87.5 & 1.14 & $\mathrm{~N}$ & $\mathrm{~N}$ & $\mathrm{~N}$ \\
\hline 45 & $\mathrm{~F}$ & 21 & 112.5 & 0.89 & $\mathrm{~N}$ & $\mathrm{~N}$ & $\mathrm{~N}$ \\
\hline 46 & $\mathrm{~F}$ & 53 & 192.5 & 0.52 & III & IV & $\mathrm{N}$ \\
\hline 47 & $\mathrm{~F}$ & 6 & 75.0 & 1.33 & $\mathrm{~N}$ & $\mathrm{~N}$ & $\mathrm{~N}$ \\
\hline 48 & $\mathrm{M}$ & 31 & 137.5 & 0.73 & $\mathrm{~V}$ & $\mathrm{~N}$ & P. aeru \\
\hline 49 & M & 21 & 112.5 & 0.89 & $\mathrm{~N}$ & $\mathrm{~N}$ & P. aeru \\
\hline 50 & $\mathrm{M}$ & 38 & 155.0 & 0.65 & $\mathrm{~N}$ & $\mathrm{~N}$ & $\mathrm{~N}$ \\
\hline
\end{tabular}


Table I. Continued.

\begin{tabular}{|c|c|c|c|c|c|c|c|}
\hline \multirow[b]{2}{*}{ No. } & \multirow[b]{2}{*}{ Sex } & \multirow[b]{2}{*}{ Age (months) } & \multirow{2}{*}{$\begin{array}{c}\text { Bladder } \\
\text { volume (ml) }\end{array}$} & \multirow{2}{*}{$\begin{array}{l}\text { SonoVue } \\
\text { concentration (\%) }\end{array}$} & \multicolumn{2}{|c|}{ VUR degrade } & \multirow[b]{2}{*}{ Urine culture } \\
\hline & & & & & $\mathrm{L}$ & $\mathrm{R}$ & \\
\hline 51 & M & 33 & 142.5 & 0.70 & $\mathrm{~N}$ & $\mathrm{~N}$ & $\mathrm{~N}$ \\
\hline 52 & M & 45 & 172.5 & 0.58 & $\mathrm{~N}$ & $\mathrm{~N}$ & $\mathrm{~N}$ \\
\hline 53 & M & 5 & 72.5 & 1.38 & $\mathrm{~N}$ & $\mathrm{~N}$ & $\mathrm{~N}$ \\
\hline 54 & M & 11 & 87.5 & 1.14 & $\mathrm{~N}$ & $\mathrm{~N}$ & $\mathrm{~N}$ \\
\hline 55 & M & 6 & 75.0 & 1.33 & IV & V & E. faeci \\
\hline $56^{\mathrm{b}}$ & M & 7 & 77.5 & 1.29 & $\mathrm{~N}$ & $\mathrm{~N}$ & E. cloa \\
\hline 57 & M & 28 & 130.0 & 0.77 & $\mathrm{~N}$ & $\mathrm{~N}$ & $\mathrm{~N}$ \\
\hline 58 & M & 14 & 95.0 & 1.05 & $\mathrm{~N}$ & V & $\mathrm{N}$ \\
\hline 59 & M & 23 & 117.5 & 0.85 & $\mathrm{~N}$ & $\mathrm{~N}$ & $\mathrm{~N}$ \\
\hline 60 & M & 24 & 120.0 & 0.83 & III & $\mathrm{V}$ & E. coli \\
\hline 61 & M & 6 & 75.0 & 1.33 & $\mathrm{~N}$ & $\mathrm{~N}$ & $\mathrm{~N}$ \\
\hline 62 & M & 49 & 182.5 & 0.55 & Abs & IV & $\mathrm{N}$ \\
\hline 63 & M & 108 & 330.0 & 0.30 & $\mathrm{~N}$ & $\mathrm{~N}$ & $\mathrm{~N}$ \\
\hline 64 & M & 30 & 135.0 & 0.74 & $\mathrm{~N}$ & $\mathrm{~N}$ & $\mathrm{~N}$ \\
\hline 65 & M & 33 & 142.5 & 0.70 & $\mathrm{~N}$ & $\mathrm{~N}$ & $\mathrm{~N}$ \\
\hline 66 & M & 110 & 335.0 & 0.30 & $\mathrm{~N}$ & $\mathrm{~N}$ & $\mathrm{~N}$ \\
\hline 67 & M & 7 & 77.5 & 1.29 & $\mathrm{~N}$ & $\mathrm{~N}$ & $\mathrm{~N}$ \\
\hline 68 & M & 81 & 262.5 & 0.38 & $\mathrm{~N}$ & $\mathrm{~V}$ & Stap. \\
\hline 69 & M & 18 & 105.0 & 0.95 & III & $\mathrm{V}$ & M. subsp \\
\hline 70 & M & 15 & 97.5 & 1.03 & IV & $\mathrm{N}$ & $\mathrm{N}$ \\
\hline 71 & M & 16 & 100.0 & 1.00 & $\mathrm{~N}$ & $\mathrm{~N}$ & $\mathrm{~N}$ \\
\hline 72 & M & 6 & 75.0 & 1.33 & $\mathrm{~N}$ & $\mathrm{~N}$ & $\mathrm{~N}$ \\
\hline 73 & M & 4 & 70.0 & 1.43 & $\mathrm{~N}$ & $\mathrm{~N}$ & $\mathrm{~N}$ \\
\hline 74 & M & 15 & 97.5 & 1.03 & IV & $\mathrm{N}$ & S. malt \\
\hline 75 & M & 6 & 75.0 & 1.33 & $\mathrm{~V}$ & $\mathrm{~V}$ & E. coli \\
\hline 76 & M & 2 & 65.0 & 1.54 & V & $\mathrm{V}$ & E. faeca \\
\hline 77 & M & 28 & 130.0 & 0.77 & II & $\mathrm{N}$ & $\mathrm{N}$ \\
\hline 78 & M & 81 & 262.5 & 0.38 & $\mathrm{~N}$ & $\mathrm{~V}$ & $\mathrm{~N}$ \\
\hline 79 & M & 22 & 115.0 & 0.87 & IV & $\mathrm{V}$ & $\mathrm{N}$ \\
\hline 80 & M & 37 & 152.5 & 0.66 & $\mathrm{~N}$ & $\mathrm{~N}$ & $\mathrm{~N}$ \\
\hline 81 & M & 6 & 75.0 & 1.33 & IV & IV & E. faeci \\
\hline 82 & M & 16 & 100.0 & 1.00 & $\mathrm{~N}$ & $\mathrm{~N}$ & $\mathrm{~N}$ \\
\hline 83 & M & 80 & 260.0 & 0.38 & $\mathrm{~N}$ & $\mathrm{~N}$ & $\mathrm{~N}$ \\
\hline 84 & M & 37 & 152.5 & 0.66 & II & III & $\mathrm{N}$ \\
\hline 85 & M & 8 & 80.0 & 1.25 & $\mathrm{~N}$ & $\mathrm{~N}$ & $\mathrm{~N}$ \\
\hline 86 & M & 9 & 82.5 & 1.21 & $\mathrm{~N}$ & $\mathrm{~N}$ & $\mathrm{~N}$ \\
\hline 87 & M & 20 & 110.0 & 0.91 & $\mathrm{~N}$ & $\mathrm{~N}$ & $\mathrm{~N}$ \\
\hline 88 & M & 8 & 80.0 & 1.25 & $\mathrm{~N}$ & $\mathrm{~N}$ & $\mathrm{~N}$ \\
\hline 89 & $\mathrm{M}$ & 155 & 447.5 & 0.22 & $\mathrm{~N}$ & IV & $\mathrm{N}$ \\
\hline 90 & M & 119 & 357.5 & 0.28 & $\mathrm{~N}$ & $\mathrm{~N}$ & $\mathrm{~N}$ \\
\hline
\end{tabular}

${ }^{a}$ Left repetitive kidney with hyronephrosis; ${ }^{b}$ complication of the neurogenic bladder; Abs, kidney absence; N, negative; VUR, vesicoureteral reflux; L, left kidney; R, right kidney; F, female; M, male; E. coli, Escherichia coli; K. pneu, Klebsiella pneumoniae; E. faeca, Enterococcus faecalis; E. faeci, Enterococcus faecium; P. aeru, Pseudomonas aeruginosa; S. malt, Stenotrophomonas maltophilia; Stap., Staphylococcus; M. subsp, Morganella morganii subspecies; E. cloa, Enterobacter cloacae.

Statistics results. The results indicated that there was no statistical difference in detection rate of VUR between male and female patients (Table IV; P>0.05) or between left and right ureters $(\mathrm{P}>0.05$; Table $\mathrm{V})$. 
Table II. VUR results with ultrasound contrast-enhanced voiding urosonography in children.

\begin{tabular}{lcrrrr}
\hline & & \multicolumn{3}{c}{ VUR diagnosis } & \\
\cline { 3 - 5 } Gender & Number & Left & Right & Bilateral & Total (\%) \\
\hline Male & 43 & 4 & 5 & 8 & $17(39.53)$ \\
Female & 47 & 7 & 7 & 13 & $27(57.45)$ \\
Total & 90 & 11 & 12 & 21 & $44(48.89)$ \\
\hline
\end{tabular}

VUR, vesicoureteral reflux.

Table III. Grading of VUR with ultrasound contrast-enhanced voiding urosonography.

\begin{tabular}{lrrrrrrr}
\hline & & \multicolumn{5}{c}{ VUR } \\
\cline { 3 - 6 } Gender & PPUs & I & II & III & IV & V & Total (\%) \\
\hline Male & 85 & 0 & 2 & 3 & 8 & 12 & $25(29.41)$ \\
Female & 93 & 3 & 7 & 11 & 14 & 5 & $40(43.01)$ \\
Total & 178 & 3 & 9 & 14 & 22 & 17 & $65(36.52)$
\end{tabular}

PPU, Pyelo-Ureteral Units; VUR, vesicoureteral reflux.

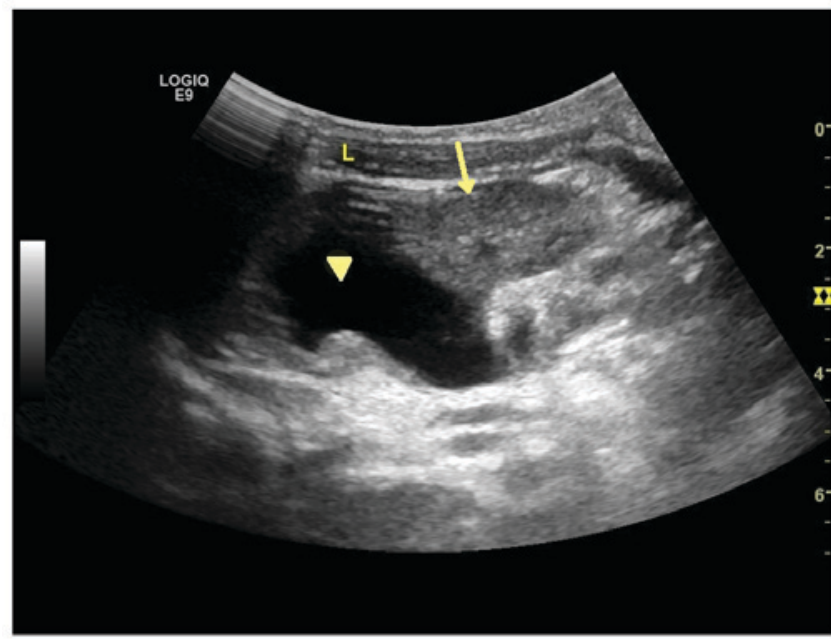

Figure 1. Two-dimensional ultrasound image of repetitive kidney, which has left side complication with hydronephrosis. The upper collecting system is separated with reciprocal connection of the echo-free region (arrow head), while the lower collecting system is not separated (arrow). L, left; R, right.

\section{Discussion}

It has been proposed that chronic kidney disease in children with VUR is derived from primary scar formation or the development of kidney abnormalities (renal dysplasia and hypoplasia), while VUR is only accompanied by developmental abnormality (13-15). VCUG is considered to be the gold standard for VUR diagnosis; however, its application is limited in children for a number of reasons,

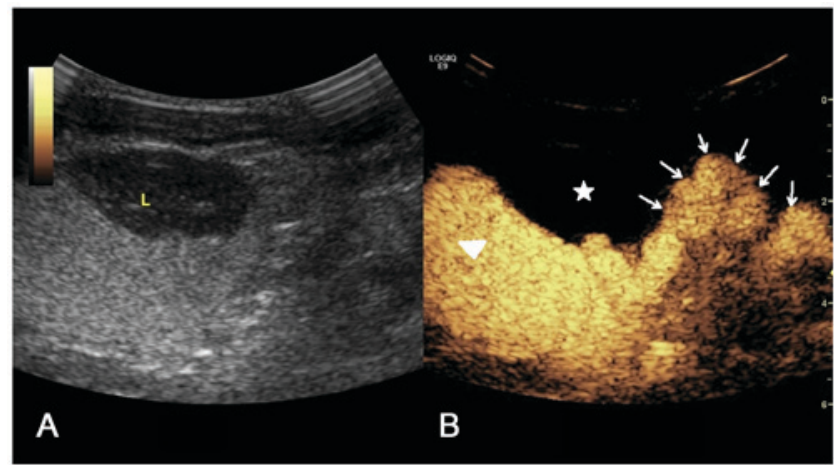

Figure 2. (A) Two-dimensional ultrasound image and (B) contrast-enhanced voiding urosonography images of the kidney in which the left side exhibits complication with hydronephrosis. A contrast agent was present in the upper collecting system (arrow head) and an expanded tortuous ureter was observed (arrow). The contrast agent did not appear in the lower collecting system (star).

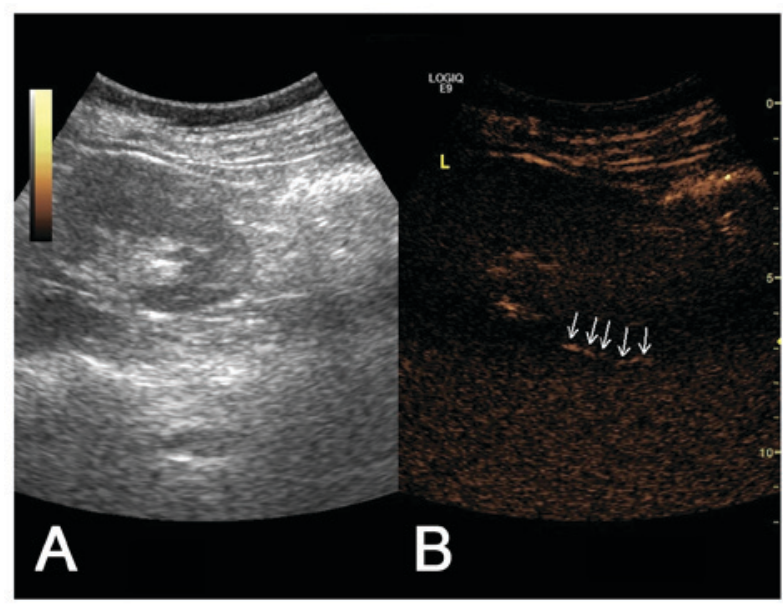

Figure 3. (A) Two-dimensional ultrasound image and (B) contrast-enhanced voiding urosonography image of a Grade I vesicoureteral reflux on the left side. The contrast agent appeared intermittently in the ureter (arrow) but not in the pelvis.

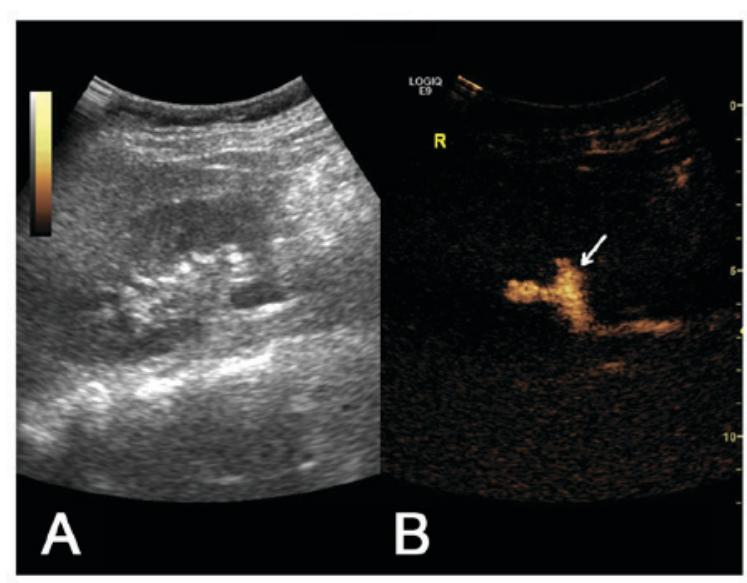

Figure 4. (A) Two-dimensional ultrasound image and (B) contrast-enhanced voiding urosonography image of a Grade II VUR on the right side. Contrast agent appeared in the pelvis and ureter without expansion of the pelvis (arrow).

including clinical sensitivity, detection rate and radiation exposure (16). In 1997, the American Urology Association 


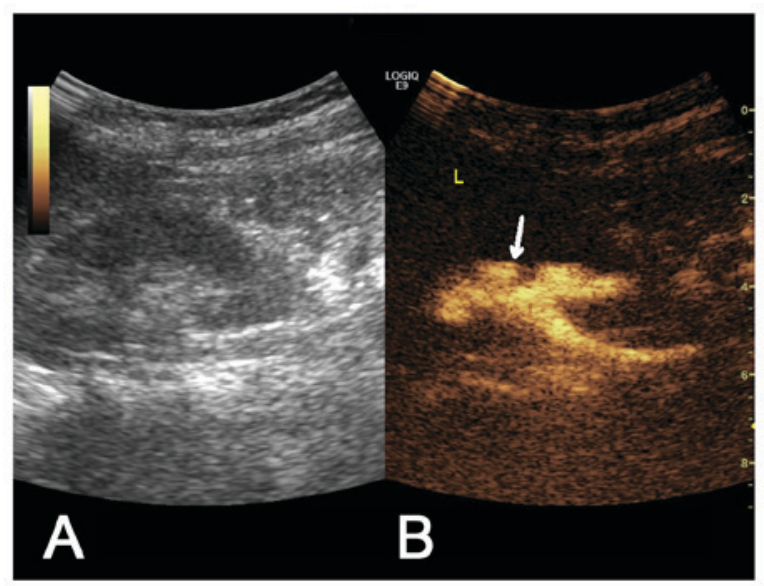

Figure 5. (A) Two-dimensional ultrasound image and (B) contrast-enhanced voiding urosonography image of a Grade III vesicoureteral reflux on the left side. Contrast agent appeared in the pelvis and ureter with mild expansion of the pelvis (arrow).

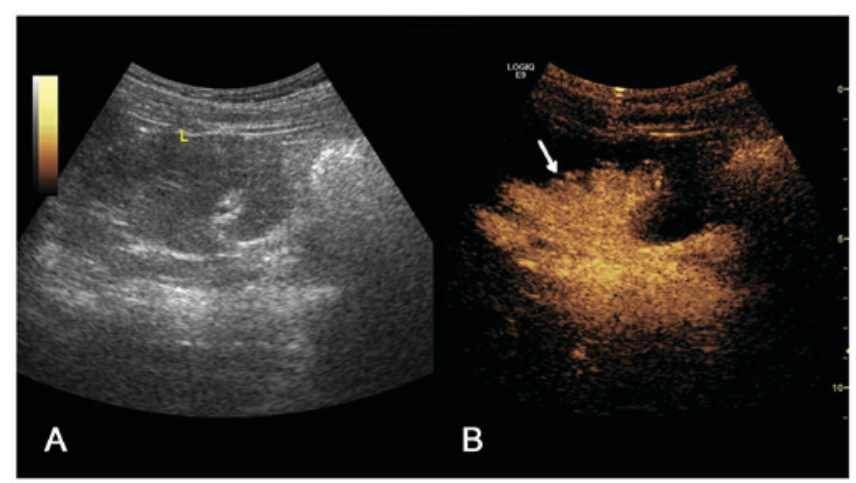

Figure 6. (A) Two-dimensional ultrasound image and (B) contrast-enhanced voiding urosonography image of a Grade IV vesicoureteral reflux on the left side. Contrast agent appeared in the pelvis and ureter with expansion of the pelvis and the appearance of carunclulae papillaris (arrow).

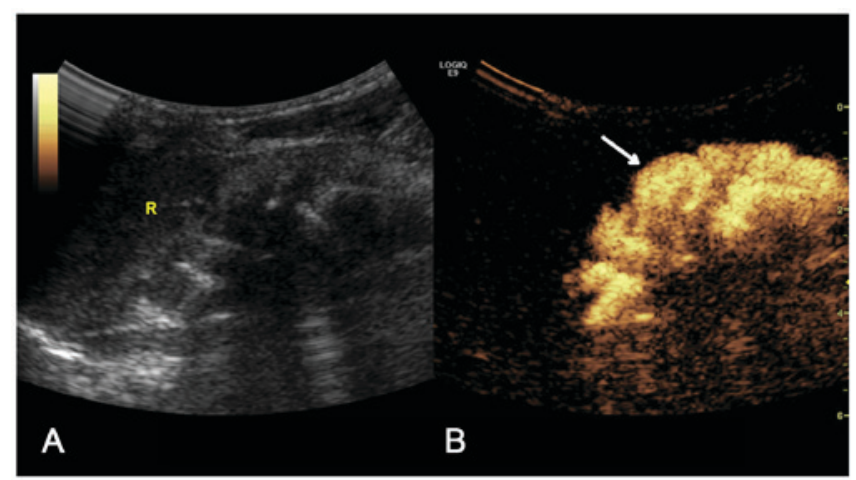

Figure 7. (A) Two-dimensional ultrasound image and (B) contrast-enhanced voiding urosonography image of a Grade $\mathrm{V}$ vesicoureteral reflux on the left side. The contrast agent appeared in the pelvis and ureter with clear expansion of the pelvis and calices, and disappearance of carunclulae papillaris (arrow).

proposed a VCUG diagnostic strategy with minimal side effects (7). Following this, a number of studies have indicated that CeVUS has a higher sensitivity compared with VCUG. The application of harmonic ultrasound further enhanced the specificity of CeVUS in the diagnosis of VUR (11),
Table IV. Comparison of ureter number and case number with VUR between different genders of children.

\begin{tabular}{lcrr}
\hline Gender & VUR+ & VUR- & \multicolumn{1}{c}{ Total } \\
\hline Male & $25(17)$ & $60(26)$ & $85(43)$ \\
Female & $40(27)$ & $53(20)$ & $93(47)$ \\
Total & $65(44)$ & $113(46)$ & $178(90)$ \\
\hline
\end{tabular}

The contents of the brackets represent the number of cases. VUR, vesicoureteral reflux.

Table V. Comparison of VUR number between left and right ureters of children.

\begin{tabular}{lcrr}
\hline Orientation & VUR+ & VUR- & Total \\
\hline Left & 32 & 56 & 88 \\
Right & 33 & 57 & 90 \\
Total & 65 & 113 & 178 \\
\hline
\end{tabular}

VUR, vesicoureteral reflux.

making it a reliable diagnostic method in Europe (17). In the present study, $44 / 90$ children $(48.79 \%)$ and $65 / 178$ PUUs (36.52\%) were diagnosed as VUR positive using CeVUS, which is consistent with a previous study (18) and suggests that $>50 \%$ of high-risk children were VUR negative. VCUG results for 2 children indicated that they were VUR negative, whereas CeVUS later revealed that they were positive for VUR. Although a comparative study was not performed, this suggests that CeVUS has an increased sensitivity compared with VCUG.

Following the development and clinical application of second-generation contrast agents and high definition ultrasound apparatus, CeVUS has been widely used to diagnose VUR in children $(19,20)$. By combining with VCUG, CeVUS has partially replaced VCUG. Large comparative studies have indicated that the sensitivity of CeVUS is significantly increased compared with VCUG, reaching $80-100 \%(9,11,21,22)$. In the present study, children who were demonstrated to be negative for VUR by CeVUS examination were also negative for VUR in the VCUG examination, while 2 children who were determined to be negative for VUR by VCUG were later diagnosed with unilateral Grade III VUR using CeVUS scanning. These results are consistent with a previous study (23) and suggest that VCUG is not sensitive enough to diagnose Grade III VUR due to its intermittent scanning (19).

Of the 25 children with a positive urine culture, 20 were diagnosed as being VUR positive, including 19 children (95\%) with Grade III or higher VUR and 11 children (55\%) with Grade V VUR. The patients with Grade V VUR and positive urine culture accounted for $78.57 \%$ of the 14 children with Grade V VUR, which suggests that there is an association between positive urine culture and VUR. Therefore, the authors suggest that preliminary VUR screening with CeVUS 
should be performed on all children with $>10^{5}$ bacterial number in urine cultures.

Large-scale pediatric studies have not directly associated adverse responses in SonoVue with CeVUS $(24,25)$. In 2008, the World Federation for Ultrasound in Medicine and Biology and the European Ultrasound Association published guidelines for its clinical application (25), while Safe Examination Guidelines for Children were launched in 2033 (26). These guidelines are which are widely used to diagnose pediatric VUR in European and American countries. In the present study, 90 children did not exhibit any adverse responses to CeVUS examination, which is indicative of the high safety of CeVUS. VUR was clearly observed (cases 3, 7 and 89) when the contrast agent was used at $0.22-0.3 \%$, which was markedly lower than the first generation contrast agent used by Darge et al (27). The authors the use of $1 \mathrm{ml}$ SonoVue for screening VUR with CeVUS in Chinese children, which is consistent with a previous report (11) and meets the recommended standard (25).

In summary, the present study supports the safety and efficacy of CeVUS as an innoxious and sensitive tool for screening VUR in high-risk children. It has been recommended as the first-choice for screening and follow-up of VUR diagnosis and urethral diseases in children and should include screening of the kidney and bladder via the perineum to identify urethral diseases.

\section{References}

1. Roić G, Roić AC, Palcić I, Grmoja T and Batos AT: Contrast enhanced voiding urosonography (cevus) in the diagnosis of vesicoureteral reflux. Lijecnicki Vjesnik 138: 39-46, 2016 (In Croatian).

2. Coulthard MG: Vesicoureteric reflux is not a benign condition. Pediatr Nephrol 24: 227-232, 2009.

3. Venhola M and Uhari M: Vesicoureteral reflux, a benign condition. Pediatr Nephrol 24: 223-226, 2009.

4. Subcommittee on Urinary Tract Infection: Reaffirmation of AAP clinical practice guideline: The diagnosis and management of the initial urinary tract infection in febrile infants and young children 2-24 months of Age. Pediatrics 138: pii: e20163026, 2016.

5. Kenda RB, Kenig A, Novljan G, Ponikvar R and Ponikvar JB: Cyclic voiding urosonography for detecting vesicoureteric reflux in renal transplant recipients. Nephrol Dial Transplant 16 2229-2231, 2001.

6. Lim R: Vesicoureteral reflux and urinary tract infection: Evolving practices and current controversies in pediatric imaging. AJR Am J Roentgenol 192: 1197-1208, 2009.

7. Darge K: Voiding urosonography with US contrast agent for the diagnosis of vesicoureteric reflux in children: An update. Pediatr Radiol 40: 956-962, 2010.

8. Ji LN, Cao L, Chen DK, Cui YC, Zhang YL, Ye H, Hao CS and Yuan XY: Evaluation of the clinical and imaging examination in high-risk children with vesicoureteral reflux. Zhonghua Er Ke Za Zhi 49: 282-286, 2011 (In Chinese).

9. Kljucevsek D, Battelino N, Tomazic M and Kersnik Levart T: A comparison of echo-enhanced voiding urosonography with X-ray voiding cystourethrography in the first year of life. Acta Paediatr 101: e235-e239, 2012.

10. Wong LS, Tse KS, Fan TW, Kwok KY, Tsang TK, Fung HS, Chan W, Lee KW, Leung MW, Chao NS, et al: Voiding urosonography with second-generation ultrasound contrast versus micturating cystourethrography in the diagnosis of vesicoureteric reflux. Eur J Pediatr 173: 1095-1101, 2014.
11. Papadopoulou F, Anthopoulou A, Siomou E, fremidis S, Tsamboulas C and Darge K: Harmonic voiding urosonography with a second-generation contrast agent for the diagnosis of vesicoureteral reflux. Pediatr Radiol 39: 239-244, 2009.

12. Papadopoulou F, Anthopoulou A, Siomou E, Efremidis S, Tsamboulas $\mathrm{C}$ and Darge K: Harmonic voiding urosonography with a second-generation contrast agent for the diagnosis of vesicoureteral reflux. Pediatr Radiol 39: 239-244, 2009.

13. Craig JC, Irwig LM, Knight JF and Roy LP: Does treatment of vesicoureteric reflux in childhood prevent end-stage renal disease attributable to reflux nephropathy? Pediatrics 105: 1236-1241, 2000.

14. Marra G, Oppezzo C, Ardissino G, Daccò V, Testa S, Avolio L, Taioli E and Sereni F; ItalKid Project: Severe vesicoureteral reflux and chronic renal failure: A condition peculiar to male gender? Data from the ItalKid Project. J Pediatr 144: 677-681, 2004.

15. Jackson EC: Urinary tract infections in children: Knowledge updates and a salute to the future. Pediatr Rev 36: 153-166, 2015.

16. Pohl HG and Belman AB: The 'top-down' approach to the evaluation of children with febrile urinary tract infection. Adv Urol 2009: 783409, 2009.

17. Giordano M, Marzolla R, Puteo F, Scianaro L, Caringella DA and Depalo T: Voiding urosonography as first step in the diagnosis of vesicoureteral reflux in children: A clinical experience. Pediatr Radiol 37: 674-677, 2007.

18. Alshamsam L, Al Harbi A, Fakeeh K and Al Banyan E: The value of renal ultrasound in children with a first episode of urinary tract infection. Ann Saudi Med 29: 46-49, 2009.

19. Papadopoulou F, Efremidis SC, Oiconomou A, Badouraki M, Panteleli M, Papachristou F and Soteriou I: Cyclic voiding cystourethrography: Is vesicoureteral reflux missed with standard voiding cystourethrography? Eur Radiol 12: 666-670, 2002.

20. Chand DH, Rhoades T, Poe SA, Kraus S and Strife CF: Incidence and severity of vesicoureteral reflux in children related to age, gender, race and diagnosis. J Urol 170: 1548-1550, 2003.

21. Darge K: Diagnosis of vesicoureteral reflux with ultrasonography. Pediatr Nephrol 17: 52-60, 2002.

22. Darge K, Zieger B, Rohrschneider W, Ghods S, Wunsch R and Troeger J: Contrast-enhanced harmonic imaging for the diagnosis of vesicoureteral reflux in pediatric patients. AJR Am J Roentgenol 177: 1411-1415, 2001.

23. Carovac A, Zubovic SV, Carovac M and Pasic IS: Significance of sonographically demonstrated ureteral dilatation in evaluation of vesicoureteral reflux verified with voiding urosonography in children with urinary tract infection. Acta Inform Med 23: 268-272, 2015.

24. Papadopoulou F, Ntoulia A, Siomou E and Darge K: Contrast-enhanced voiding urosonography with intravesical administration of a second-generation ultrasound contrast agent for diagnosis of vesicoureteral reflux: Prospective evaluation of contrast safety in 1,010 children. Pediatr Radiol 44: 719-728, 2014.

25. Claudon M, Cosgrove D, Albrecht T, Bolondi L, Bosio M, Calliada F, Correas JM, Darge K, Dietrich C, D'On ofrio, et al: Guidelines and good clinical practice recommendations for contrast enhanced ultrasound (CEUS)-update 2008. Ultrasound Med Biol 34: 11-29, 2013.

26. Piscaglia F, Nolsøe C, Dietrich CF, Cosgrove DO, Gilja OH, Bachmann Nielsen M, Albrecht T, Barozzi L, Bertolotto M, Catalano O, et al: The EFSUMB Guidelines and recommendations on the clinical practice of contrast enhanced ultrasound (CEUS): Update 2011 on non-hepatic applications. Ultraschall Med 33: 33-59, 2012.

27. Darge K, Moeller R T, Trusen A, Butter F, Gordjani N and Riedmiller H: Diagnosis of vesicoureteric reflux with low-dose contrast-enhanced harmonic ultrasound imaging. Pediatr Radiol 35: 73-78, 2005.

This work is licensed under a Creative Commons Attribution-NonCommercial-NoDerivatives 4.0 International (CC BY-NC-ND 4.0) License. 